\title{
Finite element simulation, safety assessment and countermeasure of the coke drum leaning process during the quenching stage
}

\author{
LI Zheng-liang ${ }^{1, a}$, WANG He-hui ${ }^{1, b}$, LIU Wei ${ }^{1}$, ZHOU Jin-shui ${ }^{2}$, Zhang \\ Guang-quan $^{3}$ \\ ${ }^{1}$ East China University of Science and Technology, Shanghai 200237, China \\ ${ }^{2}$ Shanghai Baosteel Chemical Co., Ltd, Shanghai 200942, China \\ ${ }^{3}$ Baosteel Engineering \& Technology Group Co.,Ltd, Shanghai 200942 \\ alizh_engliang@163.com, bhhwang@ecust.edu.cn
}

Keywords: Coke drum; Cooling stage; Tilt; Side channel; Cold spot

\begin{abstract}
The coke drum with a side channel at the beginning of cooling was simulated numerically using ANYSY, and the time history of the stress and strain fields were also acquired with indirect coupling method. The calculation results indicate that temperature stress and bending stress caused by the cold spots will cause bulging of the shell and the tilt of coke drum. With the coke drum tilting, the shell at the skirt seat will yield and the coke drum was in a dangerous state. The results of ANSYS show that the reinforcement of arc plate can effectively reduce the membrane stress on the skirt. The side channel and reinforcement of arc plate serve as the analysis for coke drum leaning and design of the skirt seat.
\end{abstract}

\section{Introduction}

Coke drums are vertical pressure vessels used in the delayed coking petroleum refineries and normally they are arranged in pairs, with alternating cycles between two drums [1]. In routine operation, coke drums experience preheating filling stage、steam cooling、water cooling and coke removal. In preheating stage, the empty coke drum in heated to $350^{\circ} \mathrm{C}$ by injecting steam followed by hot vapor into the drum. In filling stage, the hot feed material, with a temperature ranging from $440^{\circ} \mathrm{C}$ to $500^{\circ} \mathrm{C}$, is injected. At the end of the filling stage, a concentrated carbon material is produced and remains within the drum. After the coke has reached a predetermined level within the drum, usually $67 \%$ of the drum `s capacity. Following this, these coke drums are cooled by vapor then a high rate of quenched water is injected into the drum, cooling the drum to an appropriate temperature. After the water cooling, the coke is cut by high pressure water from coke cutter.

Coke drums experience severe cyclic thermal and mechanical loadings and appear drums tilt、 convex deformation and skirt cracking in the process of operation. The useful life of coke drums is much shorter than the designed value. At present, some researches had been carried out on the coke drums. But it is mainly aimed at the temperature field, convex deformation and skirt cracking of coke drums. For example, Zhong Wenzhen [2] analyzes the deformation mechanism of coke drums by using the bending theory of cylindrical shell. It is found that a periodical plastic residual deformation occurs in the quenching processes and increases with the running cycles of coke drums. The bulging deformation of coke drums mainly results from the progressive plastic deformation. Chen Sunyi [3] analyzes stress caused by the circumferential uneven temperature with the analytical and FEM. It is found that the circumferential uneven temperature field is one of the main factors of the sway and the slack of the anchor bolt nut of the tower. Ju Feng [4] analyzed the elastic plastic behavior of a coke drum subjected to both thermal and mechanical loadings based on abaqus. It is found that cold spots occured in the quenching process will cause bulging of the shell. Wang Zheng [5] simulated the temperature field of the coke drum`s working process by ANSYS. It is found that temperature change rate is high and the trend of thermal gradient variation is complex during the quenching process.

The middle channel model of coke had been used in the above research, without taking into 
account the impact of uneven distribution of coke on the deformation of the tower. There is no paper on the quantitative safety evaluation and effective control measures for the tilt of coke drum in the quenching processes.

Tilt of the coke drums researched in this paper happened in the quenching process and restoration to the original positon after the coke removal. The direction and size of the coke drums tilt are random, the maximum displacement at the top of tilt reached $160 \mathrm{~mm}$, after fastening bolts, the maximum tilt in $90 \mathrm{~mm}$. At the same time, it is found that when the coke drum produces different kinds of coke, the tilt of the coke drum will be different. Compared to asphalt coke with compact structure, the needle coke with the loose structure can cause more severe tilt of the coke drum. The periodic tilt of coke drum is not only harmful to the safe life, but also may cause the pipeline accident. Therefore, it is of great significance to study the tilt of coke drums at the quenching process. Based on the results of previous studies, a branched channel coke model is developed to study the tilt of coke drums at quenching stage by ANSYS. The variation of thermal stress and thermal deformation was calculated by the indirect coupling method. The results that the axial and circumferential temperature uneven distribution caused by the cold spots will make the coke drums bend at the quenching stage. With the coke drum tilting, the shell at the skirt seat will yield and the coke drum was in a dangerous state. The results of ANSYS show that the reinforcement of arc plate aimed at the insufficient strength of the skirt can effectively reduce the membrane stress on the skirt.

\section{Finite element model of coke drum}

\section{Branched channel model of coke.}

Foreign researchers have conducted studies on coke structure. Pohokinko [6] pointed out: When the axial feeding is adopted, the fluid coke tends to from the axial main channel and branched channel. These channels will remain at the end of the coking cycle due to the continuity of the movement. Great Lakers of Carbon [7] researched the structure of needle coke from the coke drums. They put forward“dendritic structure”. Due to the existence of nonuniform and random channeling flows of water through the residual coke mass during the quenching stage, certain locations of drum shell may be cooled down earlier than the surrounding areas, causing cold spots in the shell. Cold spot attacks may induce significant temperature differences and gradients in the structure, resulting in excessive stresses and strains. However, the middle channel without branched channel was widely used in scholars. In this paper, the branched was used to analyze the tilting process of coke drums in quenching stage. Figure 1 shows the coke model. The height of the coke layer is $2 / 3$ of the coke drums. The diameter is equal to the inner diameter of the tower. The diameter is chosen to be $320 \mathrm{~mm}$ for the middle channel and $70 \mathrm{~mm}$ for the branched channel.

Figure 2 shows the geometry of a real coke drum. The overall height and diameter of the coke drum are respectively $23888 \mathrm{~mm}$ and $4850 \mathrm{~mm}$. The thickness of the base layer is $32 \mathrm{~mm}$ for course 1 , and $28 \mathrm{~mm}$ for course 2, and $26 \mathrm{~mm}$ for course 3, while the thickness of clad is $3 \mathrm{~mm}$ for all courses. The materials for the clad and the shell are respectively TP410S stainless steel and $14 \mathrm{Cr} 1 \mathrm{MoR}$ low alloy steel. The material for the skirt is Q345R and the thickness is $18 \mathrm{~mm}$. Their mechanical and thermal properitie are given in reference [8].

The bottom of the skirt supported by ribs has great rigidity and it is no deformation. By increasing the elastic modulus of the supporting material, it can be used to simplify the modal. In this paper, the 20 nodes 3D solid elements (solid 186) was used in the thermal analysis. To correspond with solid186, solid90 was used in the structural analysis. The mesh of the coke drum is shown in figure 3. The number is 596810 for elements, 1039925 for nodes, 5952890 for free degrees. 

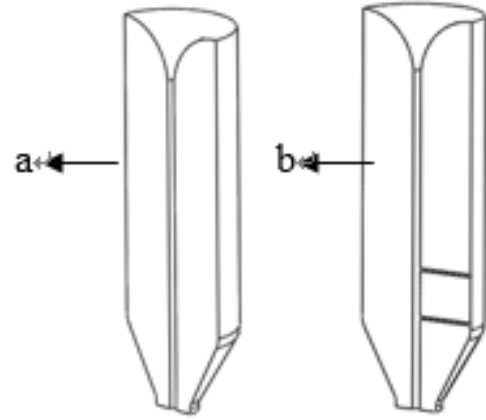

Fig. 1 middle channel model (a) and branch channel model (b)

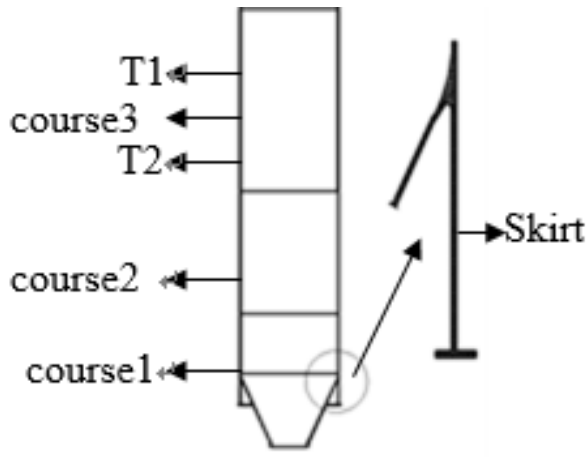

Fig. 2 geometry model of coke drum

\section{Analysis of transient temperature field in coke cooling stage}

Temperature change rate is high and the trend of thermal gradient variation is complex during water-cooling stage. It is the most dangerous time for the coke drum. At the beginning of the water-cooling stage, the coke drum tilted. In this paper, the transient temperature field of coke drum is simulated.

The temperature field at the end of steam cooling is used as the intial temperature field water-cooling stage. Temperature boundary condition is treated as follows: the adiabatic boundary condition is applied on the symmetry plane. The convective heat transfer coefficient of the insulation layer surface with the $20^{\circ} \mathrm{C}$ air is $10 \mathrm{~W} /\left(\mathrm{m}^{2} \cdot \mathrm{K}\right)$. The temperature of upper tower (T1、T2) and cooling water (T3) is known from operation date, as given in table 1 . The convective heat transfer coefficient is $2.5 \times 10^{5} \mathrm{~W} /\left(\mathrm{m}^{2} \cdot \mathrm{K}\right)$ for coke layer surface with cooling water, and 100 $\mathrm{W} /\left(\mathrm{m}^{2} \cdot \mathrm{K}\right)$ for upper tower with cooling water. According to this, the temperature field of the cooling-water stage is shown in figure 4.

Table 1 temperature of measurement points at water cooling stage

\begin{tabular}{|c|c|c|c|c|c|c|c|c|}
\hline $\mathrm{T} /$ time & $\mathrm{t}=0 \mathrm{~h}$ & $\mathrm{t}=0.5 \mathrm{~h}$ & $\mathrm{t}=1 \mathrm{~h}$ & $\mathrm{t}=1.5 \mathrm{~h}$ & $\mathrm{t}=2 \mathrm{~h}$ & $\mathrm{t}=2.5 \mathrm{~h}$ & $\mathrm{t}=3 \mathrm{~h}$ & $\mathrm{t}=3.5 \mathrm{~h}$ \\
\hline $\mathrm{T} 1 /{ }^{\circ} \mathrm{C}$ & 296 & 255 & 214 & 201 & 187 & 174 & 160 & 135 \\
\hline $\mathrm{T} 2 /{ }^{\circ} \mathrm{C}$ & 345 & 314 & 283 & 263 & 242 & 222 & 201 & 140 \\
\hline $\mathrm{T} 3 /{ }^{\circ} \mathrm{C}$ & 97 & 76 & 42 & 57 & 71 & 86 & 100 & 73 \\
\hline
\end{tabular}

The axial temperature on the left side of coke drum covering by coke is first increases and then decreases. Due to the existence of branched channel, the location of branched channel was cooled down earlier than the surrounding areas. The cooling water through these branched channel, the temperature is $50^{\circ} \mathrm{C}$ for these locations, but $200^{\circ} \mathrm{C}$ for the surrounding areas. In the radial direction, the temperature of both sides increase from inside to outside.

\section{Stress analysis of coke drum}

\section{Constraint and loading.}

The internal pressure of $0.02 \mathrm{MPa}$ is imposed on the internal surface of the coke drum. The self weight of the coke drum material is considered by an acting gravitational force in vertical direction and a coke drum material density of $7850 \mathrm{~kg} / \mathrm{m}^{3}$ was used. The weight of the coke and quenched water were considered. The density of combination of coke and water is assumed to be $1481 \mathrm{~kg} / \mathrm{m}^{3}$ and this load is imposed as a hydrostatic pressure in the inner drum surface. The structural boundary conditions as follows: the $\mathrm{Z}$ displacement of meridian plane is zero. The underside of base-ring is ALL DOF. 

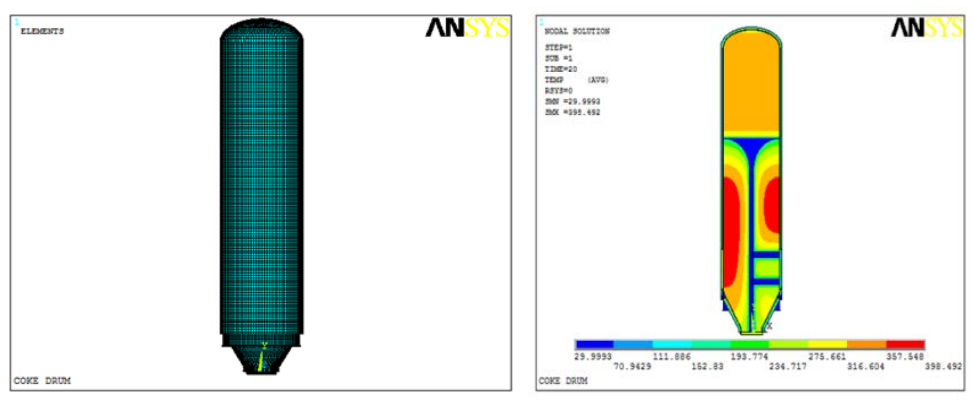

Fig. 3 finite element mesh of coke drum

Fig. 4 temperature field of quenching stage

\section{Coke tower deformation analysis.}

The deformation of the coke column in the water-cooled stage is shown in figure 5 . The maximum displacement is $68.7 \mathrm{~mm}$ (DMX in figure) for the middle channel, $76 \mathrm{~mm}$ for the branched channel. There is no tilt for the middle channel model. At the beginning, tilt of the coke drum is $23 \mathrm{~mm}$ for the branched channel and $31 \mathrm{~mm}$ at the end of the cooling-water stage. Compared with the middle channel, it is known that the branched channel caused the tilt of coke drum. Water through the channel during the quenching stage, certain locations would be cooled down earlier than the surrounding areas, causing cold spots. Cold spots caused the uneven distribution of thermal stress make the coke drum bend and tilt.

\section{Stress analysis of coke drum.}

The stress intensity of the tilted coke drum is research emphasis. Compared figure 10 with 11, the maximum stress at the skirt is increased by $80 \mathrm{MPa}$ for the coke drum tilting. Based on the JB4732, the membrane stress of skirt up to 403MPa. It is higher than yield strength of Q345R. The maximum stress of perforated areas reached $242 \mathrm{MPa}$ and the membrane stress is as high as 155.5MPa. In addition, the maximum stress for the boundary area is $182 \mathrm{MPa}$, but the membrane stress is only 73.2MPa. The stress in other areas of the coke drum is very low.

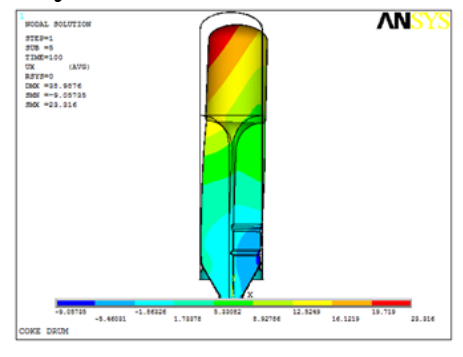

a. initial time

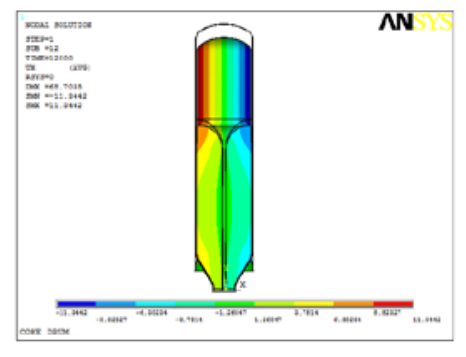

b.initaial time

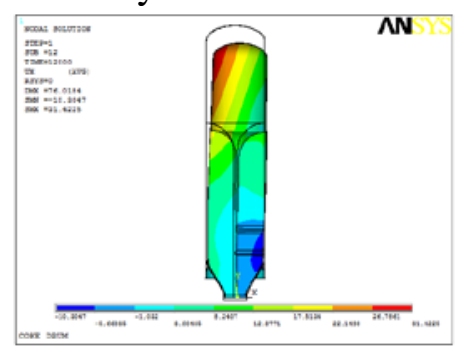

c.at the end

Fig. 5 horizontal displacement of branch channel model (a,c) and middle channel (b)

\section{Design of skirt reinforcement}

It is known that the skirt is insufficient strength. In this paper, reinforcement of arc plate was adopted to reduce the membrane stress of skirt. The 3D modal for the reinforcement of arc plate are depicted in figure 6. Due to the existence of reinforcement of arc plate, the membrane stress of skirt reduced to 219MPa from 403MPa. It is shown that the reinforced plate arc is an effective reinforcement measures. 

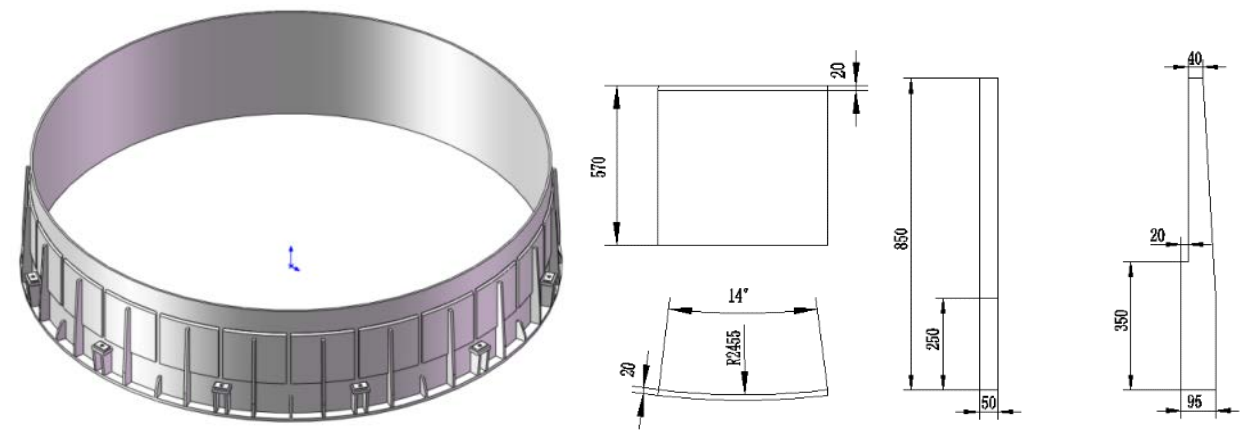

Fig. 6 3D modal of skirt with arc plate and size structure of arc plate stiffened plate

\section{Conclusions}

A finite element model of coke drum with branched channel was established to know the tilted process of coke drum at the quenching stage. It is known that temperature stress and bending stress caused by the cold spots will cause bulging of the shell and the tilt of coke drum. With the coke drum tilting, the shell at the skirt seat will yield and the coke drum was in a dangerous state. The reinforced plate arc is an effective reinforcement measures to reduce the membrane stress of skirt.

Field research from Japanese enterprises, it is known that loosing foundation bolt can effectively reduce the bending stress of skirt. But the displacement of coke drum will be bigger. So in the premise of ensuring the safety of the gas pipeline, it is one of the feasible solutions.

\section{References}

[1] Liu Renhuai, Ning Zhihua. Deformation of coke tower bulging and cracking prediction mechanism and fatigue life research progress of [J]. pressure vessel, 2007,02:1-8.

[2] Zhong Wenzhen, Wang Fan, Xia Wei, Liu Renhuai. Analysis of deformation mechanism of coke tower [J]. Journal of South China University of Technology (NATURAL SCIENCE EDITION), 2008,04:29-34.

[3] Chen Sunyi, Lin Jianhong, Wu Dongdi, Liu Cengdian, Gu Wangping. Study on characteristics of tower wall temperature field in coke (three) - to [J]. pressure vessel, effect of temperature difference on the verticality of the tower body 2001, 06:8-11+1.

[4] Feng Ju, John Aumuller, Zihui Xia and Pierre Du Plessis .Global and Local Elastic-Plastic Stress Analysis of Coke Drum Under Thermal-Mechanical Loadings[J]. Pressure Vessel Technol, 2011, 133(6), 061202-061211.

[5] Wang Zheng, Zheng Jing, Mao Qingfei, Wang Kui. The working process of coke drum temperature field simulation analysis of [J]. pressure vessel, 2011,04:28-34.

[6] Pohokinko petroleum coke [M]. Li Chenglin, transl. Beijing: Sinopec press, 1992:67-79.

[7] Ellis Pau J, Hardlin, Edward E. How Petroleum Delayed Coke Forms In A Drum [J]. Light Metals,1993:509-515.

[8] GB 150.2-2011, pressure vessel second part: material [S]. 